\title{
Planeta azul (Rodríguez de la Fuente, 1968-1974): un laboratorio del documental moderno de naturaleza
}

\author{
José CABEZA \\ Universidad Rey Juan Carlos \\ jose.cabeza@urjc.es
}

Recibido: 04/02/2014

Aceptado: 10/03/2014

\begin{abstract}
Resumen
Este artículo analiza los recursos narrativos y el material documental que se emitió en Planeta azul (19681974). Félix Rodríguez de la Fuente visionó, seleccionó y dirigió el montaje de las escenas documentales que compró TVE para este programa pero no filmó las imágenes, lo cual limita este estudio a dos apartados. Primero, permite ver las características del documental de naturaleza de la época (grandes depredadores, protagonismo humano, imágenes de impacto...). Y, en segundo lugar, Rodríguez de la Fuente explora las posibilidades del montaje y de la estructura narrativa para lograr un producto televisivo científico y entretenido, y que marcará las decisiones de producción que tomará posteriormente en El Hombre y la Tierra.
\end{abstract}

Palabras clave: Documental de naturaleza, Planeta azul, documental científico, programación TVE, Rodríguez de la Fuente.

\section{Planeta azul (Rodríguez de la Fuente, 1968-1974): a laboratory for the modern nature documentary}

\begin{abstract}
This article will analyze both the narrative strategies and filming material that was broadcasted in Planeta azul (1968-1974). Félix Rodríguez de la Fuente reviewed, selected and assambled the sequences from the documentaries that TVE decided to buy, but he did not film the sequences himself, so this limitation forces us to study just two issues. First of all, we can discover all the basis characteristics of the nature documentary from that time (big predators, human inteaction, impact images...). And, secondly, Rodríguez de la Fuente explored different ways to devised vivid montages playing with narrative structure, in order to get an entertained and scientific television programme. Later, this would be quite important to think over and make El Hombre y la Tierra.
\end{abstract}

Keywords: Nature documentary, Planeta azul, scientific documentary, TVE program, Rodríguez de la Fuente.

Referencia normalizada: CABEZA, José (2014): “Planeta azul (Rodríguez de la Fuente, 1968-1974): un laboratorio del documental moderno de naturaleza)". Estudios sobre el Mensaje Periodístico, Vol. 20, Núm. especial, pp. 193-208. Madrid, Servicio de Publicaciones de la Universidad Complutense.

Sumario: 1. Introducción y metodología. 2. Ver ya no es suficiente. 3. El protagonista humano en el mundo animal. 4. Blue chip documentaries: animales deseados, animales no tan deseados. 5. Conclusión y reflexión. 6. Referencias. 7. Material audiovisual.

\section{Introducción y metodología ${ }^{1}$}

La bibliografía existente sobre la obra de Félix Rodríguez de la Fuente no es escasa, pero sí irregular. Casi todos los trabajos destacan por una lectura biográfica, en la que

1 Este artículo es parte del proyecto de investigación Televisión y cultura popular durante el Franquismo: programación, programas y consumo televisivo (1956-1975) (HAR201127937), subvencionado por el Ministerio de Ciencia e Innovación. También es producto del programa de creación y consolidación de grupos de investigación de la Universidad Complutense: Historia y estructura de la comunicación y el entretenimiento (940439). 
sobresale la figura del propio Rodríguez de la Fuente y queda más relegado el estudio pormenorizado de sus diferentes documentales. Entre las 6 obras que hay editadas en esta línea destaca, por pionero, el trabajo de Joaquín Araujo: Félix Rodríguez de la Fuente. La voz de la naturaleza (1990) o Félix Rodríguez de la Fuente. El "amigo de los animales", que nos mostró los secretos de la naturaleza (1991). Y también la última obra, publicada por la Fundación Rodríguez de la Fuente: Félix Rodríguez de la Fuente. Su vida, mensaje de futuro (2010). Aquí, Benigno Varillas recoge cartas de gran interés para entender las limitaciones con las que trabajó Rodríguez de la Fuente en Planeta azul y su deseo constante de modificar, en la medida de lo posible, el formato del programa para poder filmar material y hacer un mejor producto televisivo. Al final no pudo hacer lo que después sí conseguiría en El Hombre y la Tierrra: tener el control de toda la producción. De ahí que esta última serie documental -más allá de su éxito de audiencia- sea objeto de un estudio más profundo en la bibliografía, aunque con resultados muy dispares. Rodríguez Jiménez, en Así se hizo. El Hombre y la Tierra (2006), aporta datos relevantes, pero la elaboración que hace de ellos está muy lejos de una línea científica, y opta por unir insidias con una legítima posición crítica por las decisiones que toma Rodríguez de la Fuente en las diferentes fases de pre-producción o producción. En segundo lugar, está la obra científica más específica, exhaustiva y amplia: El documental de divulgación científica sobre la naturaleza: técnicas narrativo-dramáticas y retóricas empleadas por Félix Rodríguez de la Fuente en El Hombre y la Tierra. Su autora, Miriam Salcedo de Prado, se centra en una extensa contextualización del documental de divulgación científica sobre naturaleza, incluye un pertinente acercamiento biográfico a la figura de Rodríguez de la Fuente y analiza la producción de El Hombre y la Tierra, así como los recursos narrativos y las técnicas retóricas que utiliza el autor para construir los episodios de la serie. Este estudio se ha utilizado como referencia. El objetivo de esta investigación es probar que las ideas que se plasman en El Hombre y la Tierra asoman, nacen o se perfilan en Planeta azul, lo cual confiere importancia a esta serie para entender el surgimiento y la maduración del concepto de documental que después desarrolló Rodríguez de la Fuente.

Planeta azul o El Planeta azul, la serie más larga que produjo TVE en el ámbito de la divulgación científica, tiene varias etapas delimitadas por 4 títulos diferentes: Animalia (1 capítulo), Vida salvaje (31 capítulos), Fauna (52 capítulos) y Planeta Azul (158 capítulos)2. Rodríguez de la Fuente definía sus funciones dentro de Fauna -y, por extensión, de todos los programas citados- de forma muy amplia: "asesor científico, prospector cinematográfico, guionista, director cinematográfico y locutor-pre-

2 Según el material existente en el Archivo Histórico de Radio Televisión Española (RTVE) únicamente hay un programa emitido con el nombre de Animalia. Sin embargo, el análisis de la programación de la propia TVE publicado en prensa refleja hasta 9 episodios que llegaron a anunciarse con la citada nomenclatura. Martín, Juan, La programación de la segunda cadena de TVE durante el franquismo 1966-1975, Universidad Complutense (tesis en fase de elaboración). 
sentador" (Varillas, 2010: 438). A pesar de los cambios de nombre ${ }^{3}$, la estructura del programa, de apenas media hora de duración, siempre fue la misma. Rodríguez de la Fuente abría el espacio con una presentación de duración variable. Después, él mismo, en voz en off, conducía el programa y comentaba dibujos y mapas o las imágenes que procedían de productoras como Survival ITC, Metromedia o de grabaciones hechas por el equipo del programa a propósito de un tema específico. Así, aunque la nomenclatura era distinta, estas emisiones sobre documentales científicos de naturaleza mantuvieron siempre una única unidad estructural, "y no sufrieron ninguna evolución en su contenido"4.

Se han visionado, vaciado y analizado 23 programas de Planeta azul, Fauna y Vida salvaje, lo que representa un 9,5\% del total de documentales (242 capítulos) de la serie, que se emitió entre el 20 de octubre de 1968 y 30 de marzo de 1974. La selección del material se estableció según diversos criterios. Primero, se buscaron programas editados con un intervalo de tiempo amplio entre ellos, pero que se ocuparan monográfica o ampliamente del mismo animal. Así se hizo, por ejemplo, con el elefante (El ocaso de los elefantes, 2/5/1970, Vida salvaje; Los elefantes, 10/2/1969, Fauna; El elefante (Parte 1), 16/12/1972 y (Parte 2), 23/12/1972, Planeta azul) o el hipopótamo (Hay demasiados hipopótamos, 27/7/1970, Vida salvaje / El mundo del hipopótamo (Parte 1), 29/9/1973 y (Parte 2) 3/10/1973, Planeta azul). El objetivo era no variar el animal objeto de estudio para intentar descubrir evoluciones narrativas o de tipo de filmación en el material documental con el que se trabajaba. En segundo lugar, se tuvo muy en cuenta la tendencia, ya clara a partir de los años 60, de producir los llamados "blue chip documentary", que buscan filmar grandes depredadores y escenas espectaculares para atraer a las audiencias televisivas. Se trataba de comprobar en qué medida Planeta azul asumía el desafío de producción que exigen este tipo de documentales (El león (Parte 1) 27/4/1969, Fauna; El león (Parte 2), 4/5/1969, Fauna, y El león (Parte 3) 11/5/1969, Fauna). En tercer lugar, se eligieron grupos de animales con características diversas para comprobar si se podía establecer una idea narrativa común o si había peculiaridades en los relatos que tuvieran que ver con el tipo de fauna que se filmaba: aves de presa (El águila imperial, 8/6/1969 y El águila imperial, 24/11/1973), fauna marina (La agonía del mar [Parte 1, 3, 7 y 8, 1971]), reptiles (El retorno de los dragones, 13/12/1969, Vida salvaje; Los dragones, 10/2/1973, Planeta azul) y mamíferos (Los lobos, 4/1/1971, Planeta azul).

Los diferentes episodios se han analizado desde un punto de vista narrativo, con el fin de valorar si se cuentan buenas historias o si éstas tienen deficiencias. En otras palabras, si se relata el ciclo completo de la vida del animal, y qué momentos se excluyen o cuáles dan idea definitiva de cómo es y cómo vive la fauna protagonista. Este análisis se apoya en el concepto de acción y de su creciente influencia en los documentales de naturaleza. La constante en los documentales de divulgación científica siempre ha

3 Las vicisitudes y las decisiones que marcaron el cambio del nombre del programa se pueden encontrar en Varillas, Benigno (2010) Félix Rodríguez de la Fuente. Su vida, mensaje de futuro. Madrid: La esfera de los libros, pp. 446-456 y 498-99.

4 Ficha de la serie El planeta Azul, Archivo Histórico de RTVE. 
sido trabajar más sobre el mundo animal que sobre el comportamiento vegetal. Esta tendencia se explica en la facilidad de contar historias de animales que llevan a cabo acciones concretas (comer, cazar, moverse...), frente al estatismo en el mundo vegetal y el consecuente aburrimiento que puede proyectar su filmación en un formato audiovisual (Francés i Doménech, 2002: 17). En términos dramáticos, una acción es un intento para lograr algo, un objetivo sencillo y claro: «cualquier cosa más difícil de conseguir que abrir una ventana no es y no puede ser una acción» (Mamet, 2011: 73).

Las acciones de los animales se han clasificado en los siguientes grupos: Comer, Cazar, Luchar, Amar, Jugar y Hacer. En Comer se reúnen las escenas en las que un animal se alimenta. A veces está acción está inmediatamente ligada a Cazar, pues el depredador, por ejemplo, puede comenzar a comer inmediatamente después de abatir a la pieza, incluso simultáneamente. También hay que tener en cuenta que están incluidas dentro de Comer las acciones en las que un ave engulle un pez o cuando un herbívoro está comiendo hojas. En Cazar se agrupan todas las acciones en las que un animal captura a otro para comérselo. No importa el resultado, si se caza finalmente o no. Amar es un descriptor que recoge los cortejos y las cópulas de los animales. Luchar tiene dos dimensiones. Por un lado, hay animales que combaten por la primacía en el grupo o por la cópula con una hembra, y otros que se enfrentan por su vida. Jugar también es bastante tautológico: los animales juegan o, al menos, así lo subraya la voz en off. Por último, Hacer es la categoría más heterogénea e informe de todas. Cualquier otra actividad que lleve a cabo el animal, y que sea escasa o difícilmente asimilable a un grupo temático propio, queda registrada en este apartado: un gibón se desplaza (A través de la jungla, parte 1, min. 12), unos elefantes se bañan (El elefante, parte 2, Planeta azul, min. 7), un elefante se rasca en un árbol (min. 10), un elefante derriba un árbol (min. 10); unos elefantes retozan en el barro (Los elefantes, 1969, min. 12), otro se pulveriza arena (min. 13). Han quedado fuera de la clasificación acciones anodinas e intrascendentes, con poco atractivo dramático y visual, como nadar, volar, andar o movimientos corporales sin un sentido concreto identificado.

En torno a estas acciones se puede contar el ciclo completo de la vida del animal, su historia. En el análisis realizado se tiene en cuenta que no todas las acciones de los animales tienen el mismo valor narrativo.

Se valora también el papel de las imágenes fijas (dibujos básicamente) en la narración para suplir la ausencia de imágenes en movimiento, la presencia humana en la presentación de la historia, así como las diferentes formas utilizadas por el realizador para conseguir continuidad narrativa en los episodios analizados. Finalmente, se hará especial hincapié en la utilización o no de imágenes espectaculares -las referidas básicamente a los grandes depredadores- y a las estrategias para terminar los documentales en diferentes tipos de clímax. Con todo ello se demostrará la dificultad de conseguir el documento ideal de la naturaleza: aquel en el que el espectador asiste realmente a lo más representativo y llamativo que hace el animal en su ciclo vital. Todos los problemas y limitaciones -y los recursos que se usan en otros documentales-, más la experiencia posterior de la Serie Venezolana de El Hombre y la Tierra, explicarán la decisión de Rodríguez de la Fuente de potenciar, hasta el extremo que se hizo, las reconstrucciones documentales en las filmaciones de la fauna ibérica. 


\section{Ver ya no es suficiente}

Planeta azul surge en un momento histórico en el que los documentales de naturaleza están en pleno proceso de adaptación al medio televisivo, buscando fórmulas para no salirse del cauce científico, pero asumiendo que la televisión es un divertimento y que la gente tiene como objetivo primario entretenerse cuando ve un programa, aunque éste sea científico. A través de las pantallas más grandes, las del cine, los espectadores ya tenían en la memoria toda una enciclopedia animal. Al principio, la idea sobre la forma de trasladar el mundo animal a la representación audiovisual era sencilla: que el zoo llegue a casa. Ya en la década de los 30, los animales son utilizados habitualmente en las películas y de forma absolutamente caprichosa, es decir, los animales comienzan a aparecer en las historias porque la gente disfruta viéndolos, no porque sean elementos imprescindibles dentro de la trama. En Las nuevas aventuras de Tarzán (Edward A. Kull, 1935) hay una escena inexplicable desde un punto de vista puramente narrativo. En 4 minutos y 28 segundos no sucede nada vital para el relato, pero sí para el interés que podía provocar la película en el espectador. Esos minutos son un paréntesis para hacer un recorrido completo por el zoo africano: aparecen monos, elefantes, leones, pitones, cebras, ciervos, leopardos, panteras, caimanes, hipopótamos e imágenes aéreas de una manada de elefantes y de unos ñus en estampida. El cine -ficción o documental- se ocupa de mostrar al público los animales que no tiene oportunidad de ver normalmente. Lo exótico había ejercido una fuerza de atracción en el público desde los primeros tiempos del cinematógrafo. En la misma línea estaban los cines de Actualidades, donde se exhibían noticiarios y documentales, muchos de ellos centrados en la naturaleza. Durante la II República española (1931-1936), este tipo de producciones ocupaban el tercer lugar en cuanto a número de películas exhibidas dentro del género documental. Obviamente, predominaban las realizadas en zoológicos por su fácil producción. Los animales aparecían expuestos casi como en un bodegón. La imagen estaba más para satisfacer curiosidades que para dar cuenta de hallazgos científicos: Los monos (1933), La araña negra (1934) o La foca (1935) son buenos ejemplos. A veces, también adoptaban un tono más ambicioso (La vida del caballo, 1934) o incluso levemente científico (Variedad gatuna, 1933). Y tampoco era infrecuente que se intentara cautivar al espectador a través de un título llamativo: Las gigantescas culebras (1933), Los gigantes minúsculos (1934), Animales salvajes (1934) o La reina subterránea (1935) (Paz y Cabeza, 2010: 759-760).

Ver animales también llegó a la televisión, primero, a través del formato showand-tell, es decir, una transposición de los zoos con guía a la pantalla: Zoo Parade (1950, NBC), Saturday at the zoo (1950, ABC) y Meet me at the zoo (1953, CBS). Estos programas mostraban los animales y hablaban sobre sus características. Planeta azul también usó la fórmula de show-and-tell, incluso se impuso en aquellos episodios relacionados con el mar, donde las limitaciones de las filmaciones eran mucho más patentes. Sólo se emitían imágenes de animales o bien nadando o bien siendo pescados o interactuando con el hombre: tiburones (La agonía del mar, Parte 3), bogavantes, ballenas, focas, pingüinos y variedad de peces (La agonía del mar, Parte 1), placton (La agonía del mar, Parte 7)... A mediados de la década de los 50, la fórmula de show-and-tell no podía explotarse mucho más, quizás influyó en su agota- 
miento el éxito de series de ficción de aventuras, donde los animales no posaban, sino que llevaban a cabo acciones no naturales en su entorno, pero que hacían que toda la trama girara en torno a ellos y tuvieran mucho más atractivo para la audiencia, como Rin Tin Tin (1954-59) o Lassie (1954-71, CBS) (Chris, 2006: 52). Los programas documentales evolucionaron e intentaron trasladar esa idea del animal en acción al ámbito científico, pero el cambio fue paulatino, como se comprueba por algunos comentarios de Rodríguez de la Fuente sobre los límites del material que tenía que emitir en Planeta azul. En el capítulo titulado El gran Norte (min 22), el naturalista se queja de que las imágenes sobre la vida de los alces no sean de calidad, es decir, que no reflejen lo más importante en el desarrollo vital de los animales y en su lugar aparezcan los interminables planos de zoo:

"Es un mundo que no podemos enseñar mucho. Es un mundo en el que el cineasta de la naturaleza no suele penetrar con su cámara porque yo diría que es poco rentable. Es decir, para hacer una buena película de osos pardos, para hacer una buena película de alces, para hacer una buena película de lobos árticos hay que pasarse meses, quizás años en su clima [...]" (Félix Rodríguez de la Fuente, El gran Norte, de la serie El Planeta azul, minuto 22)

El lamento de Rodríguez de la Fuente revela que ver ya no es suficiente, que es necesario mostrar al animal en acción, y no sirve cualquier acción, sino sólo aquellas que sean pertinentes para explicar, en esencia, cómo vive y cómo se comporta. Mientras eso no sucedía, las historias que se relataban en Planeta azul tenían que cubrir esos huecos recurriendo a la imagen fija (los dibujos), un claro fracaso en un medio con el potencial expresivo de la televisión. En algunas ocasiones, los dibujos tenían que llegar donde las imágenes no lo hacían para mostrar acciones científicamente relevantes, y salvar el guion de la pobreza audiovisual. En El león (Parte 1, min 46) ${ }^{5}$, se acude a los dibujos para explicar cómo marcan el territorio varios animales, incluido el propio león. En Los lobos (min. 8), Rodríguez de la Fuente utiliza una lámina para enseñar cómo un lobo levanta su rabo para mostrar dominancia. Indirectamente, el uso de láminas o fotografías también servía para alargar un tema concreto y poder conseguir varios episodios cuando las imágenes apenas daban de sí tanto. En $A$ través de la jungla (Parte 3), casi la mitad del tiempo (Min. 15-27) está ocupado por una serie de dibujos que le sirven a Rodríguez de la Fuente para mostrar todos los tipos de primates que hay y resaltar sus peculiaridades anatómicas (dientes, colas y manos). Pero sin usar ninguna imagen. En El águila imperial, emitido en la época de Fauna, los dibujos que ayudan a distinguir al águila real del imperial (territorios en los que habita, aspecto, nido...) se extiende hasta los 8 minutos y 15 segundos: casi un tercio del programa en el que no se ve ni una sola imagen de un águila. Tres años después el nuevo episodio de El águila imperial, esta vez en Planeta azul, también adolece de imágenes de relleno como un halcón que se alimenta de larvas de avispa (min. 18) o un águila culebrera cazando (min. 14). Solo a través de un águila imperial que Icona trae

5 Con objeto de ayudar a su localización, la numeración de los minutos en los episodios de Planeta azul se corresponde con la existente en las cintas del Archivo Histórico de RTVE, y no con la del programa original finalmente emitido. 
de vuelta desde Estados Unidos, ya que fue sacado de forma ilegal de España, conseguimos ver el ave de presa que da título al programa.

\section{El protagonista humano en el mundo animal}

En 1953 aparece un nuevo tipo de programa. Armand Denis muestra en Londres su documental Below the Sahara, un sencillo trabajo de media hora en el que se pueden ver elefantes, leones, jirafas y todos los grandes animales del este de África. La película triunfó: "they were majestic and marvellous in their proper setting". Los espectadores quedaron encantados. La reacción de los gurús televisivos fue mecánica, según cuenta David Attenborough: "¿Por qué no hacer una serie y emitirla todas las semanas? (Attenborough, 1980: 8). Y así nació On Safari, que pronto se enfrentaría a sus propias limitaciones: se cambiaba el escenario, pero los animales seguían conservando la pasividad de los que estaban en el zoo o en un plató. Era imprescindible filmar a los animales salvajes viviendo en la naturaleza y no solo estando en ella. Para lograr algo así se requerían medios, audacia, paciencia... y creatividad.

Hacer una serie documental de larga duración que captara la vida de los animales salvajes y que respondiera a las necesidades productivas de la televisión era una utopía. Solo en los 45 minutos que duraba un documental televisivo de calidad de la BBC como The unknown forest se habían invertido más de 4 años de trabajo (Parsons, 1982: 110). Attenborough aprendió durante la filmación que lograr 20 segundos de buen material en un día era todo un éxito (Parsons, 1982: 106). Así que hubo que adaptarse: el concepto de ver animales cambió por el de la aventura de encontrarse con animales. Era la única forma de conseguir con continuidad más material y mejor material. El hombre, por primera vez, también era parte del espectáculo en un documental sobre la vida salvaje, como demostraron dos serie de éxito: Zoo Quest (1954-1963) y The Undersea world of Jacques Cousteau (1968-1976). En Zooquest, Attenborough viaja con empleados del zoo de Londres a países exóticos para capturar los animales que luego serán exhibidos ante el público. El zoo es solo el final del documental, porque los animales expuestos sin más no permiten entretener durante 30 minutos, lo que duraba un episodio. Al principio la idea era filmar el proceso de adquisición de animales para el zoo, pero el programa rápidamente derivó en expediciones a la naturaleza, en las que tampoco se podría filmar en profundidad el comportamiento animal y, por lo tanto, su peso en el material emitido no era demasiado: era todo lo que se podía hacer en expediciones que apenas llegaban a los 3 meses de media (Parsons, 1982: 46). Es decir, el viaje del hombre a la naturaleza era la historia, no los propios animales: toda una revolución narrativa.

En la misma línea está el trabajo de Cousteau y su deseo de mostrar la vida salvaje en el mar respetando la verdad documental, pero asumiendo también como desafío conseguir un producto televisivo entretenido y con una periodicidad regular. Cada episodio de The Undersea world of Jacques Cousteau, que tenía una duración aproximada de 51 minutos, el doble que uno de Planeta Azul, requería un descomunal trabajo de montaje para componer las imágenes y conseguir una buena película a pesar de la falta de "cooperación" de los animales salvajes. Sólo el trabajo de preparación del corte final de la película, una vez filmada, podía extenderse más de 10 semanas 
para cada capítulo (Van Dyke, 2006: 254). En la serie, el viaje del naturalista no era secundario, sino dramáticamente estructural. Cousteau era científico, pero también explorador, y éste último rol salvaba más minutos que el primero. Las audiencias televisivas querían ver al hombre junto a la naturaleza y también enfrentado a ella, aunque eso desviase la atención en ocasiones sobre lo puramente científico. Esto llevó a que algunos vieran en el trabajo de Cousteau deficiencias científicas y que le acusaran de pasar buena parte de los episodios haciendo "turismo": navegando, buceando y haciendo fotografías (Chris, 2006: 57). Más allá de las críticas, Costeau consiguió crear una fórmula televisiva en la que el viaje del hombre a la naturaleza era tan importante, por atractivo, como desentrañar esa naturaleza y conocer a sus habitantes. Así, los programas ya no dependían del esquivo comportamiento de los animales, sino que las acciones de los hombres también construían narrativamente la historia y, lo más importante, se podían prever, planificar y filmar.

Esta influencia humana en las estructuras narrativas también llegó a Planeta azul, aunque de forma más modesta y sin la aparición directa de Rodríguez de la Fuente: "[...] lo que más echo en falta en los documentales de Fauna es mi propia presencia en el medio en que transcurre la acción" (Varillas, 2010: 435). En dos episodios que tratan sobre el hipopótamo, pero con 3 años de diferencia, podemos apreciar la evolución del género, y cómo los avances técnicos y la invasión humana en el reino animal posibilitan que los productos finales sean más entretenidos sin perder su perfil científico. ;Hay demasiados hipopótamos! (27/7/1970, Vida salvaje) se extiende por espacio de 8 minutos con una presentación del zoo africano: elefantes en un camino, un leopardo que trepa a una rama, topis (antílopes) corriendo, un búfalo saliendo de la aguas de un lago... Luego llega el hipopótamo y llama la atención cómo conocemos los pormenores de la vida de este animal: ¡sin imágenes! Los datos científicos que se aportan no se ilustran con planos, y tiene que ser el propio Rodríguez de la Fuente el que nos cuente que van a comer por la noche a la Sabana, que marcan el territorio con orina o que luchan por los territorios. También se sirve de los dibujos o láminas para mostrar los territorios que abarcan los machos en tierra, y para explicar la postura de desafío que tienen cuando luchan entre sí. No hay pruebas audiovisuales de todo lo que se relata, y las imágenes sólo llegan al mundo del hipopótamo cuando la filmación puede ser controlada absolutamente por la intervención humana: los directores del parque deciden matar a algunos hipopótamos para controlar la sobrepoblación. Así, la impresión es que el episodio está hinchado, y que se construyó para justificar la emisión de unos pocos minutos espectaculares -interesantes, pero no muy científicos- en los que se matan hipopótamos, los tractores los arrastran para sacarlos del agua, los biólogos investigan sus cuerpos, varios hombres los trocean con un hacha y luego se hacen pinchos de carne de hipopótamo. Ese material no podía perderse por su impacto y, en torno a ello, se aprovecha para contar cómo es y cómo vive el hipopótamo (min. 8-18).

Tres años más tarde, El mundo del Hipopótamo (Parte 1 y Parte 2) tiene una configuración visual más rica, pero repite patrones narrativos. Nuevamente se usa el hipopótamo como reclamo, para cautivar y sentar a las personas frente al televisor, aunque no todas las imágenes sean de este animal, sí que se usa para vender el producto. Planeta azul emite fragmentos del documental Mzima: portrait of a Spring 
(Alan Root, 1969) 6 , realizado por Alan y Joan Root, que no trata sobre hipopótamos, sino sobre la vida salvaje de aves, mamíferos y reptiles en este área de Kenya. El documental recibió el apoyo de la crítica, un premio en el American Film Festival e incluso volvieron a hacer otro documental en Mzima para lograr el Oscar en 2003 (Mzima: Haunt of the Riverhorse). Indudablemente, el trabajo de Alan Root mejora a ¡Hay demasiados hipopótamos! porque esta vez sí que se ve al animal viviendo en su entorno salvaje: el hipopótamo camina por el fondo y algunos peces le quitan los parásitos (min. 6); dos hipopótamos se desafían abriendo la boca sin que el combate llegue a ser sangriento (min. 10), y un hipopótamo mueve la cola medio sumergida en el agua, según advierte Rodríguez de la Fuente, está depositando excrementos. Aún así, las imágenes de hipopótamos difícilmente sirven-por sí mismas para hacer un capítulo. En la primera parte, Rodríguez de la Fuente hace una presentación del tema (min. 25) en el Safari Park y rodeado de... jelefantes pequeños! y también tiene que recurrir a las láminas para explicar el ciclo vital que se dan en las aguas de Mzima, y al que contribuyen los excrementos de los hipopótamos, y la imagen imposible de los hipopótamos pastando por las noches (min. 13). En la segunda parte de El mundo del hipopótamo, paradójicamente, el hipopótamo es invisible, no trata sobre él, sino sobre los animales que viven en su entorno, cuyo seguimiento permite explotar las posibilidades de las cámaras subacuáticas de Alan Root: la pesca submarina del cormorán (min. 6), la plasticidad de las nutrias que juegan y cogen objetos (min. 14-21), el cocodrilo cogiendo a una serpiente en la orilla (min. 22) o el gran clímax: un cocodrilo despedazando un impala que Alan Root echó a las aguas para recrear una escena que se da en la naturaleza. Así, como en jHay demasiados hipopótamos!, tres años después, la intervención del hombre en la naturaleza -una vez matando hipopótamos y otra vez alimentando a un cocodrilo- sirve para crear una sucedáneo de clímax al final del capítulo, aunque en el caso del cocodrilo no tenga mucho que ver con el que era, a priori, el tema del documental. La interacción humana también se explota en forma de experimento en El león (Parte 3), al poner con un magnetofón un rugido de león macho para que vengan otros machos a disputarle el territorio (min. 48), o en El águila imperial, cuando entrenan a un águila para poder devolverlo a su entorno natural (min. 23). Hipopótamo, cocodrilo, león o águila podía parecer animales muy diferentes, pero en realidad entraban dentro de una misma categoría: eran animales que tenían prioridad para ser filmados. Empezaba la era de los blue-chip documentaries y la necesidad de buscar imágenes que fueran indudablemente atractivas para la audiencia.

\section{Blue chip documentaries: animales deseados, animales no tan deseados}

A partir de 1961, la división televisiva de National Geographic Society empieza a producir documentales sobre naturaleza (León, 1999: 88). Los nuevos programas tienen buenas audiencias, lo cual demuestra que los programas científicos también pueden interesar a un público amplio no familiarizado con este tipo de contenidos. El éxito de estos nuevos formatos se basa en una doble selección. Primero, se elige pre-

6 Rodríguez de la Fuente cita al propio Alan Root cuando vemos al hipopótamo andando por el fondo (min. 6). También habla de Mzima. 
ferentemente a aquellos animales que resulten a priori atractivos o más llamativos para la audiencia, en su mayoría, los depredadores más conocidos como el león, el tigre, el tiburón, etc. Y segundo, se opta sólo por las imágenes espectaculares, lo que se llama imágenes de «gran impacto» (León, 1999: 88), que pudieran sorprender a los espectadores por su gran fuerza visual y porque nunca antes las habían visto. Así, nace una nueva forma de hacer documentales de naturaleza para la televisión (los llamados documentales blue chip, porque cuentan con los equipos cinematográficos más avanzados del momento) que tiene sus propias convenciones narrativas: la representación de los grandes animales -especialmente los depredadores-, exquisita calidad visual, puesta en escena espectacular, estructura narrativa de los contenidos... (Bagust, 2008: 219).

Los documentales blue chip son una reacción y una respuesta a la entrada de Disney en el mundo de la naturaleza. Desde Bambi (1942), el primer largometraje de animación centrado en la vida de un animal salvaje, hasta la serie de documentales True-Life Adventures (1948-1960), en la que es raro ver a un depredador matando a una presa, Disney crea una ensoñación de la naturaleza, un lugar diseñado sin conflictos y sin muerte, controlado más para entretener que para educar. Según Bagust, los productos Disney moldearon las audiencias de los programas de naturaleza:

"[...] The longer the public was exposed to the Disney model of 'documentary' the more, it is reasonable to propose, they came to expect this kind of dramatized behavior and narrative from animal subjects" (Bagust, 2008: 218).

Series documentales como National Geographic, Wild Kingdom (1963-1988), The undersea world of Jacques Costeau (1968-1976) y, más adelante, Wild America (19821994), Nature (1982-2011) o El Hombre y la Tierra buscan una representación de la naturaleza más real y menos naif, pero se apoyan en las técnicas de filmación y de edición que incorpora Disney a la divulgación de la vida salvaje de los animales (King, 1996: 64). Así, los documentales se marcan la necesidad de atraer a los espectadores a través de los grandes depredadores, pero en los años de emisión de Planeta azul no resultaba sencillo acceder a los aspectos más espectaculares de la vida de estos animales. Rodríguez de la Fuente tenía claro lo que quería. En una carta explicaba como podía mejorar los capítulos que iba a montar sobre el león:

"Por ejemplo, la presentación del programa dedicado al león, la haría en pleno Serengeti, delante de una familia de leones que devora los restos de una cebra u otra presa. Naturalmente, siguiendo esta línea se podrían filmar presentaciones y secuencias clave de veinte o treinta especies africanas" (Varilla, 2010: 435).

Ninguna de esas imágenes aparecieron en los tres capítulos dedicados al león. No sólo porque el plan de producción era demasiado ambicioso para los recursos que TVE le asignaba a la serie en ese momento ${ }^{7}$, sino también porque en las 3 semanas que

7 Luis Ezcurra, subdirector general de TVE en 1969 le replicó en otra carta que, “(...) por mi parte, si el safari fotográfico no nos cuesta un riñón, no hay inconveniente en que lo hagas", al mismo tiempo que hablaba de "auténtica crisis de medios de producción" y alababa el ingenio y los conocimientos de Rodríguez de la Fuente para sacar adelante el programa siempre revestido "de una gran dignidad". Varillas, Benigno (2010), opus cit., pp. 436-437. 
decía Rodríguez de la Fuente que iba a estar de safari fotográfico por Uganda, Kenia y Tanzania era utópico pretender regresar con ese material. Los problemas para producir estos nuevos documentales eran múltiples. Sin duda alguna, la acción de Cazar era la que más definía a los grandes depredadores, pero la realidad era demasiado fugaz, y la cámara no podía estar allí cuando sucedía todo el proceso narrativo de cazar: el animal que acecha, la lucha expresada en la carrera de una presa que huye del depredador y la captura final. En tres episodios dedicados al león se muestra, de forma fragmentada, el momento de la caza. A veces, hay ataques frustrados, lo que significa que la escena se queda sólo en la introducción: la leona inicia la carrera para atacar a unas cebras, pero no puede acercarse mucho. Las cebras escapan (El león, Parte 2 , min 20). La leona también va detrás de una jirafa, pero no logra darle caza (El león, Parte 1, min 33). Lo mismo sucede con los ñúes. La leona ni siquiera persevera en su intento, se detiene muy pronto (El león, Parte 2, min 22); Min 39. El antílope está lejos, pero también corre y la leona ni siquiera arranca (El león, Parte 3, min 11). Rodríguez de la Fuente termina por encontrar una solución narrativa a la cantidad de escenas de cacerías inconclusas:

"¿Cazó la leona después de 15 o de 20 intentos de caza? Cazo. Pero el realizador que la observaba desde su automóvil camuflado no pudo verlo, ni lo puedo filmar. Sin embargo, el realizador acudió prestamente, corriendo a toda la velocidad de su automóvil para filmar lo que pasó después de que la leona llegara a cazar” (El león, parte 3, min. 11-12).

La leona, por fin, tiene su presa, pero la audiencia no, porque la parte más importante de la historia (la del clímax) no pudo ser filmada. A cambio tenemos a los depredadores devorando el ñu o la cebra apresados hasta en 6 escenas en los tres capítulos dedicados al león. En un 33\% de los casos (6/2) parece que el espectador llega in medias res, cuando aún queda algo de la acción de cazar: la presa aún está viva y los leones están sobre ella asfixiándola. Pero la sensación de llegar tarde es inevitable y Rodríguez de la Fuente juega con esa carencia, evidente para los espectadores: "Más rápido que la vista, como dicen los prestidigitadores" (El león, parte 2, min. 10). Filmar exclusivamente estos fragmentos postreros de la escena de caza era una situación habitual en los episodios de Planeta azul. En A través de la jungla (Parte 2, min 47) no se aprecia bien la captura de un pato. Hay un cocodrilo acechando, y antes también se encuadraron a los patos, pero de pronto aparece un plano corto en el que un pato chapotea violentamente. No se ve en ningún momento al cocodrilo. Todo es muy confuso. Unos patos se alejan del lugar y se corta abruptamente la escena.

Otra forma de conseguir una unidad narrativa en la acción de Cazar era el uso del montaje. Se crea tensión dramática con la yuxtaposición de planos, absolutamente insignificantes por sí mismos, pero unidos con habilidad y condicionados por la función de anclaje de la voz en off (o la música), para obligar al espectador a leer las imágenes de una determinada manera. Así se logra recrear situaciones que son de difícil filmación, por ejemplo, en A través de la jungla (Parte 1, min. 17-18) una pitón está deslizándose y, justo después, se ve un plano de los macacos que se mueven rápido por las ramas: "[...] en este caso parece que han burlado a su gran enemiga y vuelve la paz", aclara Rodríguez de la Fuente. También en A través de la jungla (Parte 2, min. 
45) hay una reconstrucción de una posible situación de caza. Un cocodrilo está desplazándose y se sucede la imagen de unos macacos que se asustan cuando están bebiendo. El cocodrilo parece cerca por el montaje, pero sin duda son imágenes diferentes.

La idea de montaje, en el sentido de buscar planos polisémicos que puedan dar continuidad narrativa a una buena situación filmada, se utiliza en varios capítulos. En el material documental que le llega a Rodríguez de la Fuente se comprueba que los realizadores no se conforman con grabar un momento culminante (habitualmente relacionado con la acción de Cazar), sino que también se preocupan por emplatar bien audiovisualmente la situación con planos de recursos, aunque con cierta torpeza aún. En La agonía del mar (Parte 8 [1/01/1970] se cuenta la pesca con arpón del pez espada (min 7-11), y se incluyen planos insertos en el montaje de un pez espada bajo el agua o en la superficie. Los fallos de raccord son palmarios, con lo que el montaje salta, pero al menos queda clara la prioridad de ampliar una situación y darle una continuidad narrativa.

La combinación de varios momentos y animales para poder lograr la sensación de continuidad y que se filmó una escena narrativamente completa (planteamiento - nudo - desenlace). En A través de la jungla (Parte 2, min 32), se necesitan varios ciervos se aprecia por el tamaño variable de las presas y por las diferentes líneas que tienen en el lomo- para construir el ataque de un tigre a una hembra de ciervo asiático.

Una tercera opción es la no simulación. En este caso, el documental no defiende que lo que suceda sea real. Se huye de la teatralidad y de la puesta en escena y no se esconde la intervención del equipo de rodaje. En El mundo del hipopótamo (Parte 2), Rodríguez de la Fuente trabaja con las imágenes del documental Mzima: portrait of a Spring (Alan Root, 1969), en el que se muestran tomas submarinas de cómo se desplazan los hipopótamos y también se aprovechan las cámaras subacuáticas para provocar escenas que suceden en Mzima, pero que exigían una producción descomunal para poder captarlas directamente de la realidad como, por ejemplo, ver la técnica de un cocodrilo para despedazar el cadáver de un impala que se encuentra sumergido en las aguas (min 23-24): "Y miren el impala que ha sido echado en el agua y que va a ser despedazado por el cocodrilo".

\section{Conclusión y reflexión}

Rodríguez de la Fuente deseaba que las Ciencias Naturales en televisión resultaran tan divertidas como "las películas de ciencia ficción o una película de policías" (Salcedo, 2008: 237). Todo pasaba por la generación de historias, por hacer que el espectador entendiera el mundo científico como algo fascinante, no sólo por lo que representaba en sí, sino también por la forma elegida para contárselo. Aún así el trayecto de la idea al programa ideal no fue fácil. Planeta azul era la serie documental que Rodríguez de la Fuente podía hacer en aquel momento, no la que deseaba producir, pero sí le sirvió para foguearse en la realidad televisiva: comprobar sus límites y la mejor forma de gestionarlos. Por una parte, Rodríguez de la Fuente se enfrentó a la dictadura de la programación semanal, en la que la cantidad de minutos se imponía por encima de la calidad, lo cual derivaba en programas híbridos entre el documental y la clase magis- 
tral: Rodríguez de la Fuente hablando, a veces extensamente, frente a unas láminas muy parecidas a la pizarra de un profesor. Por otra, Planeta azul exploró las claves dramáticas y narrativas del documental moderno de naturaleza: el atractivo de los grandes depredadores (blue-chip documentaries), la búsqueda de estructuras narrativas en torno a momentos muy selectivos -y espectaculares- del ciclo vital de un animal (Cazar), la incorporación de nuevas técnicas de filmación para rodar de forma no invasiva aspectos inéditos de la vida salvaje de los animales (Alan Root) y el peso de la interacción humana en la naturaleza (Cousteau) para tener la certeza de poder contar mejores historias.

Todo ello quedó reflejado en la producción de El Hombre y la Tierra. Primero, en Venezuela. La representación que se hace en los 18 capítulos de la Serie Venezolana de la vida del jaguar en la naturaleza deja algunas reflexiones. Rodríguez de la Fuente sólo dispuso de 2 meses para filmar el material y las consecuencias fueron que obtuvo menos imágenes de acción de las que necesitaría tener, como prueban las repeticiones de varias escenas (báquiro y perezoso), la recreación del intento de caza de un tapir, que nunca existió, pero que se representa como cierta, y el decisivo trabajo de montaje en las escenas más espectaculares que se reconstruyen a partir de momentos y animales diferentes. El equipo de El hombre y la Tierra logra filmar algunas imágenes de gran impacto, pero a veces no son de calidad y otras no son suficientes para crear historias completas, con principio, medio y fin, y responder así al doble deseo de la audiencia de conocer la naturaleza y ver un producto audiovisual entretenido (Cabeza y Gómez: 2012).

La solución para superar este producto, aún imperfecto, estaba en las reconstrucciones documentales. Rodríguez de la Fuente convenció al Icona (Instituto para la Conservación de la Naturaleza) para que les proporcionaran todo tipo de animales «para rodar primeros planos y escenas de predación, y que costearan la alimentación y cuidado de aquella especie de Arca de Noé en que se convirtió el campamento que montaron para disponer de un plató de rodaje al aire libre» (Varillas, 2010: 576). En Pelegrina (Guadalajara) se creó este nuevo «arca de Noé», lleno de animales en peligro de extinción y de sus presas. Allí, y no en los rodajes complementarios en la naturaleza, se filmaron los momentos más espectaculares, los que resultaban absolutamente imprescindibles para transformar los contenidos de divulgación científica en buenos relatos audiovisuales.

Con todo, si analizamos de forma descontextualizada las 1299 acciones que aparecen en los 91 capítulos de la serie Ibérica de El Hombre y la Tierra podemos llegar a conclusiones absurdas. Hay apenas un escaso $2 \%$ de acciones clasificadas como Amar (cortejo y cópula), ¿esto significa que no tiene interés el momento reproductivo o que éste apenas se produce en la vida salvaje? Luchar apenas ocupa un $4.9 \%$ ¿No hay confrontación en la naturaleza? Y, lo más destacado, ¿se puede afirmar como verdad científica que los animales dedican más tiempo a Cazar (32.1\%) que a beber, bañarse, rascarse, limpiarse y otras múltiples acciones (22.3\%)? (Cabeza y Mateos-Pérez, 2013).

Lo que revelan estos porcentajes es que los documentales de El Hombre y la Tierra no están hechos para hacer una transposición exacta de la vida de los animales en 
la naturaleza, sino para dar una idea de cómo viven seleccionando de forma prioritaria aquellas partes que son más espectaculares y que potencian más la idea de historia.

En conclusión, el sentido esencial de las reconstrucciones documentales no era otro que conseguir que todo el mundo viera, principalmente, escenas de caza: un elemento sin duda espectacular para el espectador. En una nota que Rodríguez de la Fuente dictó en 1975 para TVE deja claro que, por una parte, hay secuencias que "no habían sido filmadas en la historia del cine, e incluso podríamos afirmar que eran desconocidas hasta por los más expertos naturalistas del campo" y, por otra, que "seguramente, como consecuencia del impacto de sus imágenes, la serie ibérica alcanzará las más altas cotas de popularidad". En esta carta enviada a TVE, Rodríguez de la Fuente cita 4 escenas concretas y todas están relacionadas con la acción de cazar (Varillas, 2010: 581).

Planeta azul preparó la llegada para El Hombre y la Tierra, que representó un juego constante con los límites de hasta dónde se puede llegar para lograr que la audiencia se interese por un tema científico. En Planeta azul no solo se limitó a contar la realidad, sino también a intentar hacer de esa realidad un espectáculo en la posproducción. Con El Hombre y la Tierra, la idea era la misma, pero su aplicación más audaz e integral Si lo que sucedía en la naturaleza se contaba mal, o con malas imágenes, surgía un producto visual pobre científicamente y con menos poder dramático y, por lo tanto, menos interesante para la capacidad divulgativa de los programas y para el deseo de divertirse aprendiendo de las audiencias.

\section{Referencias}

ARAUJO, Joaquín (1990): Felix Rodríguez de la Fuente. La voz de la naturaleza. Barcelona, Salvat.

ARAUJO, Joaquín (1991): Félix Rodríguez de la Fuente. El "amigo de los animales", que nos mostró los secretos de la naturaleza. Madrid, Ediciones S.M.

ATTENBOROUGH, David (1980): The zoo quest expeditions: travels in Guyana, Indonesia and Paraguay. Guildford, Lutterworth Press.

BAGUST, Philp (2008): "Screen natures': Special effects and edutainment in 'new' hybrid wildlife documentary". Journal of Media \& Cultural Studies, Vol 22, n 2, pp. 213-226.

CABEZA, José y GÓMEZ, Salvador (2012): "El diseño de la realidad televisiva en el documental de naturaleza: El Hombre y la Tierra. Serie Venezolana (Félix Rodríguez de la Fuente, 1974)". Estudios del Mensaje Periodístico, Vol. 18, núm. 1, pp. 275-291. Madrid, Servicio de Publicaciones de la Universidad Complutense.

CABEZA, José y MATEOS-PÉREZ, Javier (2013): "Thinking about television audiences: Entertainment and reconstruction in nature documentaries". European Journal of Communication, Vbl. 28, num. 5, pp. 570-583.

CHRIS, Cynthia (2006): Watching wildlife. Minneapolis, University of Minnesota Press. 
FRANCÉS I DOMÉNECH, Miquel (2002): "Los documentales de naturaleza ayer y hoy. Realidad versus virtualidad". Telos, $\mathrm{n}^{\circ}$ 52. $2^{\mathrm{a}}$ época, pp. 17-21.

KING, Margaret J. (1996): "The audience in the wilderness: The Disney nature films". Journal of Popular Film \& Television, vol. 24, n 2, pp. 60-69

LEÓN, Bienvenido (1999): El documental de divulgación científica. Barcelona, Paidós

MAMET, David (2011): Verdadero y falso. Herejía y sentido común para el actor. Barcelona, Alba.

MARTÍN, Juan: La programación de la segunda cadena de TVE durante el franquismo 1966-1975. Madrid, Universidad Complutense (tesis en fase de elaboración)

MILLS, Brett (2010): “Television wildlife documentaries and animals' right to privacy". Journal of Media \& Cultural Studies, Vol 24, num. 2, pp. 193-202.

PARSONS, Christopher (1982): True to nature. Cambridge, Stephens.

PAZ, María Antonia y CABEZA, José (2010): "La realidad que vieron los españoles. El cine de no ficción durante la Segunda República (1931-1936)”. Hispania, Vol. 7, no 236, pp. 737-764.

RODRÍGUEZ JIMÉNEZ, Fernando L. (2006): Así se hizo. El Hombre y la Tierra, Naturaventur.

SALCEDO DE PRADO, Miriam (2011): "El antropomorfismo como herramienta de divulgación científica por televisión". Comunicación y sociedad, vol 24, n 1 , pp. 217-246.

SALCEDO DE PRADO; Miriam (2008): El documental de divulgación científica sobre la naturaleza: técnicas narrativo-dramáticas y retóricas empleadas por Félix Rodríguez de la Fuente en El Hombre y la Tierra, (tesis doctoral). Pamplona, Universidad de Navarra

SCOTT, Karen D. (2003): "Popularizing science and nature programming: the role of spectacle in contemporary". Journal of Popular Film and Television, Vol. 31, n ${ }^{\circ}$, pp. 29-35.

VAN DYKE, Trudi (2006): "Cousteau, Jacques-Yves", en AITKEN; Ian (editor) (2006): Encyclopedia of the Documentary Film. Vol. 1 A-G. Nueva York, Routledge, pp. 254-255.

VARILLAS; Benigno (2010): Félix Rodriguez de la Fuente. Su vida, mensaje de futuro. Madrid, La esfera de los libros

\section{Material audiovisual}

- A través de la jungla (Parte 1). Fauna (17/11/1968)

- A través de la jungla (Parte 2). Fauna (24/11/1968)

- A través de la jungla (Parte 3). Fauna (1/12/1968) 
- El ocaso de los elefantes. Vida salvaje (2/5/1970)

- Hay demasiados hipopótamos. Vida salvaje (27/7/1970)

- El elefante (Parte 1). Planeta azul (16/12/1972)

- El elefante (Parte 2). Planeta azul (23/12/1972)

- Los elefantes. Fauna (10/2/1969)

- El mundo del hipopótamo (Parte 1). Planeta azul (29/9/1973)

- El mundo del hipopótamo (Parte 2). Planeta azul (3/10/1973)

- Los lobos. Planeta azul (4/1/1971)

- El león (Parte 1). Fauna (27/4/1969)

- El león (Parte 2). Fauna (4/5/1969)

- El león (Parte 3). Fauna (11/5/1969)

- El retorno de los dragones. Vida salvaje (13/12/1969)

- Los dragones. Planeta azul (10/2/1973)

- El águila imperial. Fauna (8/6/1969)

- El águila imperial. Planeta azul (24/11/1973)

- La agonía del mar (Parte 1). Planeta azul (22/3/1971)

- La agonía del mar (Parte 3). Planeta azul (5/4/1971)

- La agonía del mar (Parte 7). Planeta azul (9/5/1971)

- La agonía del mar (Parte 8). Planeta azul (16/5/1971)

- La Antártida. Vida salvaje (26/4/1970) 